\title{
An Experimental Study of Contact Temperatures at Sealing Interface against Varying Shaft Surfaces
}

\author{
Sarah Shabbir ${ }^{1,2, *(\mathbb{D})}$, Seamus D. Garvey ${ }^{2}$, Sam M. Dakka ${ }^{2} \mathbb{D}$ and Benjamin C. Rothwell ${ }^{2}$ \\ 1 Institute of Aerospace Technology, University of Nottingham, Nottingham NG7 2TU, UK \\ 2 Gas Turbine and Transmission Research Centre, Faculty of Engineering, University of Nottingham, \\ Nottingham NG7 2TU, UK; seamus.garvey@nottingham.ac.uk (S.D.G.); \\ sam.dakka@nottingham.ac.uk (S.M.D.); benjamin.rothwell@nottingham.ac.uk (B.C.R.) \\ * Correspondence: sarah.shabbir@nottingham.ac.uk; Tel.: +44-7549754237
}

Citation: Shabbir, S.; Garvey, S.D.; Dakka, S.M.; Rothwell, B.C. An Experimental Study of Contact Temperatures at Sealing Interface against Varying Shaft Surfaces.

Coatings 2021, 11, 156.

https://doi.org/10.3390/

coatings11020156

Received: 31 December 2020

Accepted: 25 January 2021

Published: 29 January 2021

Publisher's Note: MDPI stays neutral with regard to jurisdictional claims in published maps and institutional affiliations.

Copyright: (c) 2021 by the authors. Licensee MDPI, Basel, Switzerland. This article is an open access article distributed under the terms and conditions of the Creative Commons Attribution (CC BY) license (https:/ / creativecommons.org/licenses/by/ $4.0 /)$.

\begin{abstract}
Increased temperatures at the sealing interface between the seal and shaft can reduce the working life of a seal through elastomer aging, swelling and increased friction. Degradation of the seal due to increased temperatures can cause pre-mature failure, wear and leakage. There is no such thing as a perfect seal; each application has requirements to cater to the needs of each system. For radial oil seals in helicopter gearboxes, the contact temperatures at the sealing interface are a critical parameter to consider. In this manuscript, investigating the factors that influence the temperatures at the contact interface shed light on the operating parameters that cause an increase in contact temperatures. Four varying shaft coatings are tested against three seal spring loads for a range of sliding velocities between $5-25 \mathrm{~ms}^{-1}$ to reproduce conditions of the gearbox. The study reveals an optimum seal spring of $12 \mathrm{oz}$, with a circumferential load of $3.34 \mathrm{~N}$ for lowest temperatures at the interface. Higher springs of $14 \mathrm{oz}$ and lower springs of $8.5 \mathrm{oz}$ both cause increased temperatures at the interface. Additionally, the need for surface coatings on the shaft is re-enforced through experimental evidence demonstrated by comparing temperatures reached between a plain stainless steel shaft and three surface coated shafts. Chrome plating shafts are undesirable due to the 'polishing' in effect they experience. The results of this study build on this by showing that chrome plated shafts have higher temperatures at the interface, aggravating any wear or polishing in of that surface. Contact temperatures with Tungsten carbide and Chrome oxide coatings remain within the expected temperature rise. Lastly, microscopically 'rougher' surfaces result in increased temperatures in contrast to surface coatings within the specified range of roughness as provided by DIN 3760/61/ISO 6194.
\end{abstract}

Keywords: radial-lip oil seals; sealing interface; sleeves; surface coating; garter spring pre-load; helicopter gearbox; contact temperatures

\section{Introduction}

Radial Seals are rotary oil seals to prevent lubricant leakage out of a system. While the primary purpose of such components is to prevent leakage out, they also ensure that debris and other contaminants do not enter the system. They mount the shaft with an interference fit and are used in both, static and dynamic sealing applications. In this application, the seals remain stationary as they slide on the shaft surface as the shaft rotates, creating a dynamic seal. Figure 1 below is an image of a radial lip seal, demonstrating the various parts it consists of. The seal has (1) a lip, which presses down on the surface of the rotating shaft, (2) an outer static seal, (3) a supporting metal reinforcement and (4) a garter spring with a pre-load, which provides a force for the lip to achieve sealing. This spring presses onto the seal-shaft interface to provide resistance to the fluid leaking out. 


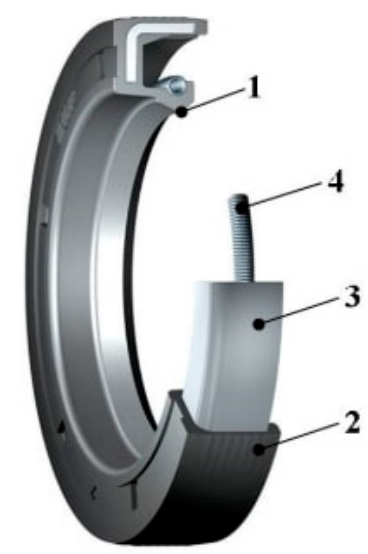

Figure 1. Radial Lip Seal Schematic [1] without dust lip to identify main components of this particular type of seal. 1. Sealing lip, 2. Outer static seal, 3. Supporting metal reinforcement, 4. garter spring.

The sealing interface is a three-part tribological interaction between the seal lip, the sleeve surface and the thin film of lubricant in between them. This interface is critical in determining the resulting sealing system, successful or unsuccessful. The 'success' of a sealing system is also subjective; a perfect seal does not exist. The success of a sealing system is determined by how well the specific needs of the application as identified by the engineers have been met [2]. Thus, there are several factors for the seal that effect the system i.e., seal material, seal radial loads, seal design and geometry, tolerances, etc. For the sleeve, factors such as coating, hardness, lead, texture, manufacturing method and surface finish all play a role in determining how the system will perform $([3,4]$ referring to ISO 6194, DIN 3760/1), also described in [5,6]. The motivation of this particular study was to understand the functional behavior of three common shaft coatings in the aerospace industry against seals of varying radial loads to learn about the factors that will affect the contact temperatures at the interface.

Various environmental factors also influence the wear, leakage, and overall performance of each sealing application. Temperatures, pressures, vibration, rotational speeds, oil selection, shaft coating and seal selection all play an important role and will eventually determine a successful or failed seal in each case $[5,6]$. The temperature at the sealing interface i.e., the contact temperature is a critical aspect of determining the operational conditions of a sealing system. Several factors influence the contact temperature, including the radial load, circumferential velocity and lubricating capacity of the fluid.

The lubricant helps in cooling at the seal interface as well. However, it is important to note that in such applications (helicopter splash lubricated gearboxes), it is difficult to predict where the oil will end up and whether the seals are receiving oil, or are running dry. Seals that run dry experience a high degree of friction and experience pre-mature wear and failure. This is also a reason a polytetrafluoroethylene (PTFE)-lined seal is studied in this application as PTFE provides excellent lubricating properties at the interface [7], in case lubricant is not reaching every seal. In reference to the seal, material is a critical factor. During selection of a seal material, the operating temperatures are essential limits to consider. Elastomers are the most commonly used seal materials, where various elastomers differ from one another based on the polymer and its' cross-linking. Additionally, elastomers exhibit viscoelastic behavior, which further enforces the significance of working temperatures of the seals in service. The glass transition temperature, $\mathrm{T}_{\mathrm{G}}$, separates the defined states of the polymer at different temperatures. Most sealing materials will have a very low glass transition temperature so that they can seal effectively as a flexible elastomer material at ambient temperature [8].

As seen in Figure 1, the seal has a lip (marked as 1) which slides on the shaft surface. The seal lip temperature plays an essential role in determining and predicting overall seal performance and life. When exposed to extremely high temperatures, the rubber material of the seal lip will experience aging, coking and swelling, thus damaging the seal [9]. 
Various rubbers have their own temperature limit, beyond which the rubber material will deteriorate. The respective aging of the rubber directly affects the useful life of the seal as well. Fluoroelastomer (FKM) rubber can usually withstand the most frictional heat and operates at a temperature range of -35 to $230^{\circ} \mathrm{C}$. However, it is important to note that the following rule of thumb applies: 'for every $10^{\circ}$ increase in temperature, aging increases by a factor between 2 and 4 . The life of that component is then decreased by that same factor'.

In reference to the sleeve, the surface coating is critical in determining the functional behavior of the sealing system. As described in depth by ISO 6194-1 and DIN 3671 [3,10], there are specific requirements for the sleeve that must be met for radial lip seals. These requirements include the hardness, the texture and lead as described in this particular manuscript. The surface coating determines the properties of the sleeve such as surface texture, wear and corrosion, hardness and thermal insulation [11], all of which are factors in final sealing performance.

Coating methods refer to the deposition process of the coating onto the metal. There are several methods of applying these coatings that include but are not limited to thermal and plasma spraying, chemical vapor deposition (CVD) and physical vapor deposition (PVD). These processes have varying outcomes on the final specimen in the form of microstructures, surface texture and durability. The desired coating method is selected based on the required functionality of the specimen [12].

The surface roughness of the sleeve is key in achieving proper lubrication at the interface, preventing the seal from running dry. Lubricant-free seal contact with the asperities also increases shear loads, friction and raises local seal surface temperature leading to thermal degradation [13]. Owing to the fact that the surface roughness is determined by the coating and coating method, the coating becomes an invaluable parameter in controlling increased temperatures at the sealing interface.

Further, due to high rotational speeds, frictional heat at the seal shaft interface and overall high sump temperatures can enhance the damage caused by thermal degradation. The heat generated by friction at the contact interface raises the seal lip temperature. An Finite Element Method (FEM) study conducted by Stakenborg [14] finds that while the rubbers are chosen such that their stiffness is not effected by the lip temperatures, for any temperatures above $100{ }^{\circ} \mathrm{C}$, the rubber stiffness will rapidly change due to physical aging, especially under a dynamic load. Datasheets for the operational limit of such seals [6] suggests that for a shaft diameter of $50 \mathrm{~mm}$, at $6000 \mathrm{rpm}$ the excess temperature should be around $40{ }^{\circ} \mathrm{C}$.

Salant [15] conducts a study to find how the aging of oil impacts the seal performance of a radial lip design. Aged rubber seals and samples are obtained to investigate the changes in material properties with respect to aging time. His work shoes that the microsurface topography of the seal lip is a critical factor in achieving successful sealing and this changes with aging time. More specifically, he found that the root mean square (RMS) roughness, known to be a good marker of the surface properties, decreases with aging time.

Additionally, similar thermal studies on rotary components conducted to study the relationship between contact temperatures and other factors of the rotary application are enlightening. Tzanakis [16] finds that a rise in the temperatures at the contact interface can directly affect the surface geometry. This can lead to severe local wear at the surfaces and thus, lubrication breakdown. The prediction and measurement of the surface temperatures of the interacting bodies is an integral step in preventing the failure of tribological systems, including radial lip seals. Additionally, the surface roughness of the components will likely affect the distribution of temperature increase during sliding contact. Given that increasing contact temperatures can enhance wear and thus, the surface roughness of the specimen, this is undesirable. Thus, there is a co-relation present between the contact temperatures and surface roughness with time, which we investigate in this manuscript as well.

Other conditions, such as misalignment of the seal and high oil viscosity can also contribute to heat generation at the lip. All these factors can result in reduced seal life and 
increase the maintenance intervals for seals. This is additionally confirmed as for every $14{ }^{\circ} \mathrm{C}$ drop in the sump temperature, the seal life can double [17]. Thus, it is clear why two alike seals can display stark differences in sealing efficiency, wear and life simply based on their location in the aero-engine [14].

In this manuscript, we investigate the contact temperatures at the sealing interface of radial lip seals sliding on rotating shafts. The contact temperatures as a function of the sliding velocity, shaft surfaces (roughness and coatings) and the seal radial loads are studied. The aim of this work is to identify the parameters that result in higher contact temperatures than expected. This study will shed light on the factors that influence temperatures at the interface for systems where controlled temperatures are essential to successful sealing.

\section{Materials}

\subsection{Sleeve}

Sleeves are economically and logistically more feasible to surface treat rather than entire shafts and are thus used for testing. Further, if there is considerable and excessive wear, only the sleeve will need replacing instead of the shaft. The sleeve rotates along with the shaft when the rig is operational as they are connected using a hydraulic coupling. Several factors determine the overall performance of the sealing system concerning the seal-mating surface i.e., the sleeve. The specific coating, hardness of the sleeve, surface roughness and the manufacturing method all play vital roles in a successful or unsuccessful sealing system.

According to DIN 3760/61 [4,10] the sleeve must be hardened to at least $45 \mathrm{HRC}$ (Rockwell hardness), and as the running speeds increase, the HRC of the shaft must too.

Hard chrome, chrome oxide and tungsten carbide coatings are some of the commonly used coatings in this particular application. Some of the common methods used to apply these coatings are Hard Chrome Plating (HCP), High Velocity Oxy Fuel (HVOF), Physical Vapour deposition (PVD) and Chemical Vapour Deposition (CVD). The various methods used to apply the coating will determine the properties and effectiveness of the coating. This will then impact how it will degrade or experience wear during its usable life.

Chrome oxide coating is applied using combustion powder thermal spraying, chrome plate $(\mathrm{CP})$ coating is applied using hard chrome plating, and the tungsten carbide coating is applied using CVD.

HVOF is a type of thermal spraying technique where particles are sprayed onto the substrate material surface at a high velocity of $600 \mathrm{~m} / \mathrm{s}$ or more with high pressure combustion energy of fuel and air (oxygen) serving as a heat source. The coating particles are in powder form and are injected into the hot gas stream resulting from the combustion process. High kinetic energy and high impact forces result in bonding of the coating and the substrate material. With chrome oxide, the HVOF process doesn't generate enough heat in the flame to melt the ceramic, so a combustion powder gun is used. It uses the same powder feed set up and attaches to the robot, but utilizes an alternative fuel which burns hotter. This type of gun has a lower velocity in the flame as compared to HVOF, which is why the porosity is higher. The porosity is controlled by the particle velocity and heat in the flame mainly. A review on plasma sprayed coatings [18] suggests some methods to reduce the porosity in chromium oxide coatings, as this may be detrimental to the application.

Hard chrome plating is an electroplating process to coat a specimen with a later of chromium. Thickness of hard chrome plating ranges from 2 to $250 \mu \mathrm{m}$. Hard chrome plating is a technique that has been in commercial production for over 50 years and which is a critical process associated with manufacturing and maintenance activities for commercial and military aircraft [19]. However, in recent years, European Union directives have highlighted economic and ecological repercussions of HCP and several industries are finding appropriate alternatives for this coating [20,21].

CVD, on the other hand is a completely different process. It is a more robust version of PVD as it provides a thicker layer of coating to protect from heat damage. While PVD uses primarily physical processes to apply source material to the substrate, CVD involves mixing 
the source material with chemicals that interact with the material to create the desired coating. This results in a chemical bonding between the two materials, leading to a more reliable and improved coating process for aerospace applications. It is an environmentally compliant and technically superior replacement for HCP and HVOF coatings, providing enhanced protection against corrosion and chemically aggressive media, wear, galling, fretting and fatigue. Hardide-A matches HCP in thickness and hardness and outperforms the material in several key properties including enhanced protection against corrosion, wear and chemically aggressive media [22]. Additionally, the tungsten carbide coating (called Hardide A) is by Hardide. It is porosity free and is an excellent alternative to HCP. According to a recent study [13], it outperforms HCP by 14 times, demonstrating excellent wear resistance. They also go as far as to refer to it as 'seal friendly', as it is qualified by Airbus as 'an environmentally friendly replacement for $\mathrm{HCP}^{\prime}$.

The four various sleeves are described below, three of which are coated and one remains uncoated.

- $\quad$ Chrome Oxide (CO): Chrome Oxide is a common shaft coating used in many industries, especially aerospace. The specified standard Ra and Rmr values: $\mathrm{Ra}=0.2 / 0.4$ and $\mathrm{Rmr}=(0.8)>70 \%$ with a $5 \%$ reference line surface finish parameters. The thickness of the coating is $0.1 \mathrm{~mm}$ and hardness to be $>55 \mathrm{HRC}$. The surface finish process is through diamond grinding. A university verified local manufacturer manufactured this sleeve. The manufacturer for this coating was a UK based company (Thermal Spray Coating, B\&B precision engineering, Huddersfield, UK).

- Chrome Plate (CP): Hard chrome plating is a common shaft coating for aerospace applications. However, due to its susceptibility to 'polishing in' with high fatigue and wear, industry is moving away from this coating [23]. The specified standard Ra and Rmr values: $\mathrm{Ra}=0.2 / 0.4$ and $\mathrm{Rmr}=(0.8)>70 \%$ with a $5 \%$ reference line surface finish parameters. The thickness of the coating is $0.25 \mathrm{~mm}$ and hardness to be $64 \mathrm{HRC}$. The surface finish process is through plunge grinding. This sleeve was acquired with the support of my industrial partner (acknowledgements).

- $\quad$ Tungsten Carbide (TC): Commonly known as 'hardide' coatings, they are gaining popularity, as they do not polish in over-time, maintaining their initial surface parameters, including roughness. These coatings provide improved wear and fatigue in contrast to other coatings. The specified standard $\mathrm{Ra}$ and $\mathrm{Rmr}$ values: $\mathrm{Ra}=0.2 / 0.4$ and $\mathrm{Rmr}=(0.8)>70 \%$ with a $5 \%$ reference line surface finish parameters. The outer diameter is case hardened to give a case depth of $0.5 \mathrm{~mm}$ and hardness to be $>55 \mathrm{HRC}$. The surface finish process is through plunge grinding. The manufacturer for this coating is Hardide, it was acquired with the support of my industrial partner (acknowledgements).

- $\quad$ Stainless Steel (SS): This sleeve represents an uncoated stainless steel shaft. The purpose of testing with this sleeve is to draw a comparison between the sleeves made to the required specifications and a regular stainless steel sleeve concerning the contact temperatures. It is also to derive results to demonstrate the need for specific surface coatings for optimum seal performance. A university verified local manufacturer manufactured this sleeve.

\subsection{Seal}

The seals tested in this experiment are radial lip PTFE-lined oil seals and three varying spring loads are used i.e., 8.5, 12, and $14 \mathrm{oz}$. 'PTFE-lined' means that this is essentially an elastomeric seal, with a PTFE coating on the lip to improve the tribological properties and lubrication at the sealing interface. The PTFE coating is a filled polymer matrix and the sealing lip is pre-loaded with an extension garter spring pressing down on the lip to ensure seal-sleeve contact to aid in static and dynamic sealing. The seal design includes a garter spring to maintain and provide the radial force of the lip on the surface of the sleeve. Due to various environmental conditions, particularly heat, the elastomer will age. However, to ensure that it will remain stable and unchanged during the service, the spring 
is heat-treated. The garter spring is tightly wound thus carries an initial tension. The sum of the force required to overcome the initial tension and the force due to the spring rate equals the total force that the spring exerts. Over the lifespan of the garter spring, even as the seal wears, it is designed to provide nearly a constant force. The calculation of applied circumferential and radial load are in 4.1.

Figure 2 below demonstrates a cross sectional schematic of the seal used in this experiment. This seal design is the current state of the art with the sealing lip, the garter spring, metal insert and dust lip (ISO 6194) [3]. As mentioned above, the sealing lip has a PTFE-coating bonded to the elastomer (visible in Figure 2 below); this PTFE coating is filled with certain materials to improve the mechanical properties of the sealing lip. While PTFE provides better lubrication at the interface due to its own properties, it is extremely soft and reinforcement with fillers elevates its' strength.

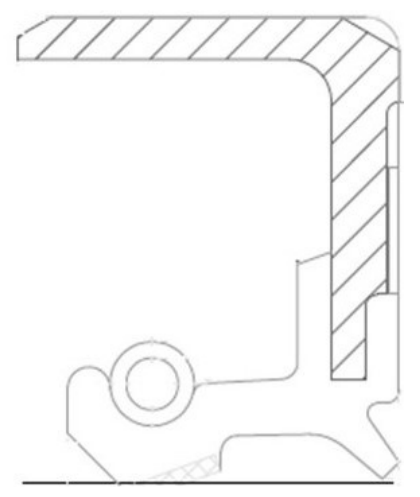

Figure 2. Engineering drawing of the exact radial lip oil seal used in this experiment, with a dust lip and a PTFE coating bonded to the elastomeric seal material.

\subsection{Lubricant}

In the case of these dynamic seals, a thin film of fluid separates the seal and the sleeve surface (2-5 microns). Leakage will depend on the application, and extent of technical tightness desired for that case (DIN 3761) [10]. In certain systems, some amount of leakage is acceptable to ensure that the seal does not run dry. The lubricant used in this study is Aeroshell 555, approved for the US military standard DOD-PRF-85734 [24]. The seal material is also approved for compatibility with this standard [25], confirming that oil and component compatibility will not arise as a problem. Table 1 below outlines the parameters of this gearbox transmissions oil used in this experiment.

Table 1. Specifications of Aero shell 555, lubricant used in experimental tests.

\begin{tabular}{cc}
\hline AEROSHELL Turbine Oil 555: Synthetic Lubricating Oil for Aircraft Turbine Engines \\
\hline Application & Approved for an increasing number of \\
Oil type & helicopter transmissions \\
Density & Synthetic ester \\
Kinematic Viscosity & Typical $994 \mathrm{~kg} / \mathrm{m}^{3}$ at $15^{\circ} \mathrm{C}$ \\
Stability & Typical $27 \mathrm{~mm}^{2} / \mathrm{s}$ at $40^{\circ} \mathrm{C}$ \\
Chemically Stable \\
\hline
\end{tabular}

Developed with high temperature and load carrying performance in mind, their viscosity at $100{ }^{\circ} \mathrm{C}$ classifies synthetic gas turbine oils like Aeroshell 555 . This oil is a $5 \mathrm{cs}$ oil, which is the most commonly used in engines for commercial aviation. $5 \mathrm{cs}$ oils are limited by a specification to a maximum of $130,000 \mathrm{cs}$ at $-40{ }^{\circ} \mathrm{C}$ and are called 'type $2^{\prime}$ ' oils. This is a reference to their viscosity grade. 


\section{Methods}

\subsection{Test Methods}

This aim of this work is to reproduce the conditions for a seal placed in the gearbox of a helicopter. In such instances, oil seals in the input and output shaft locations of a gearbox prevent loss of oil from the system as shown in Figure 3a. Figure $3 \mathrm{~b}$ shows the placement of such seals in a gearbox of this kind. These gearboxes employ a splash-lubrication technique lubricant is picked up from the base of the gearbox with the gear teeth and is thrown around as they rotate, thus lubricating the internal components. The sliding speeds of the seals vary from 5 to $25 \mathrm{~ms}^{-1}$ based on their placement within the gearbox.
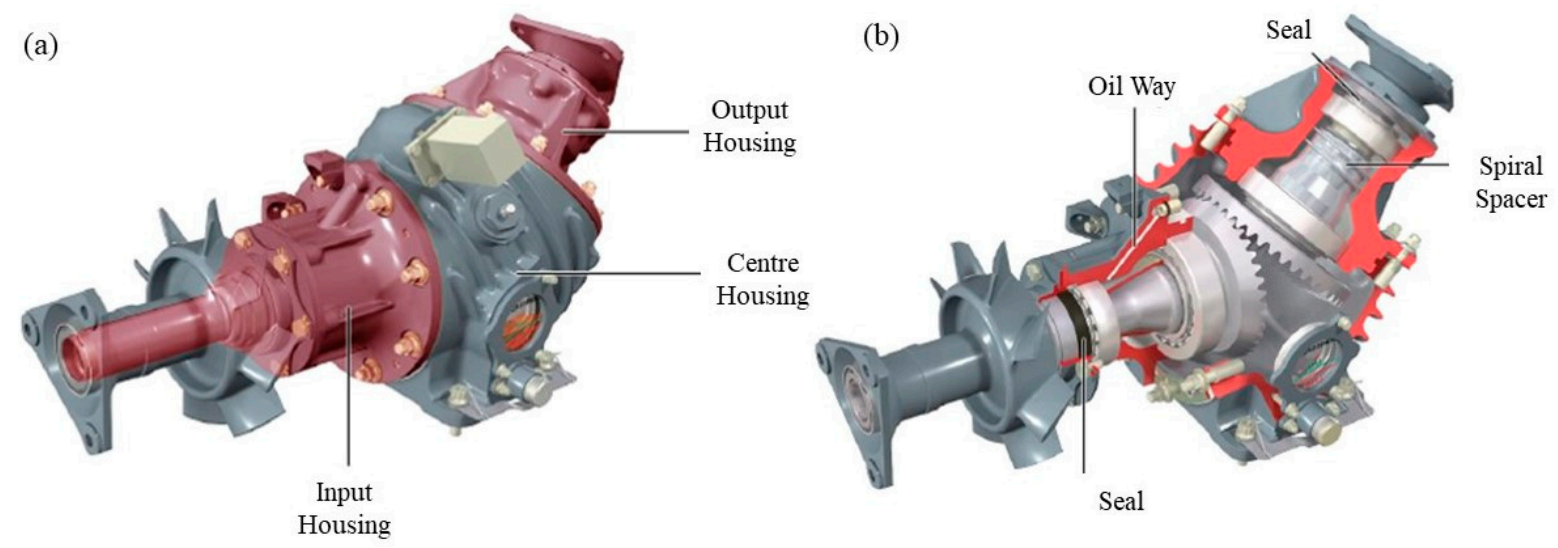

Figure 3. (a) Intermediate gearbox (IGB) schematic showing input and output housing (b) IGB schematic showing placement of seals in the input and output housing.

\subsubsection{Experimental Rig and Test Conditions}

The rig's mechanical set up consists of three main sections shown in Figure 4 below, described as follows.

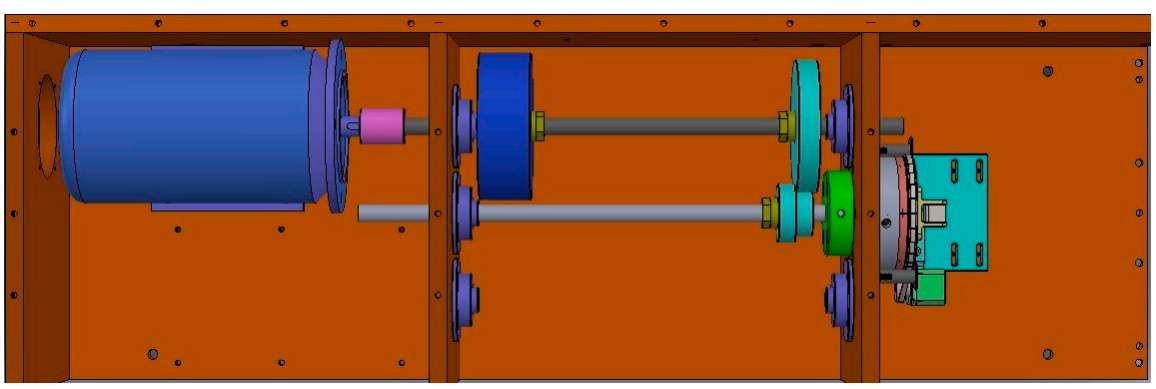

Figure 4. Top view of test rig designed displaying three sections from left to right: motor, transmissions (gears), and seal test bench.

1. The transmitted power supply (Motors): The prime motor in this rig is a $2.2 \mathrm{~kW}$ induction motor, specifications provided in Table 2 below.

Table 2. Motor Specifications.

\begin{tabular}{cl}
\hline Parameter & Value \\
\hline Rated Power & $P_{r}=2.2 \mathrm{~kW}$ \\
Poles Pair & $p=2$ \\
Frequency & $f=50 \mathrm{~Hz}$ \\
De-rated max speed & $\omega_{\max }=3000 \mathrm{rpm}$ \\
\hline
\end{tabular}


2. Drivetrain (shaft and gears): The gears are a 1:3 ratio. The input shaft is the shaft on top, connected to the motor and the output shaft is in the centre, connected to the seal test bench.

3. Seal Test bench: This is the test bench where seals are tested. Figure 5 below is a detailed schematic of this section. A stationary housing holds the seal in place as it slides on the sleeve surface. A hydraulic coupling connects the sleeve to the shaft, ensuring that the sleeve rotates along with the shaft as necessary. The stationary housing attaches onto to a Perspex chamber, filled with engine oil to simulate a helicopter gearbox.

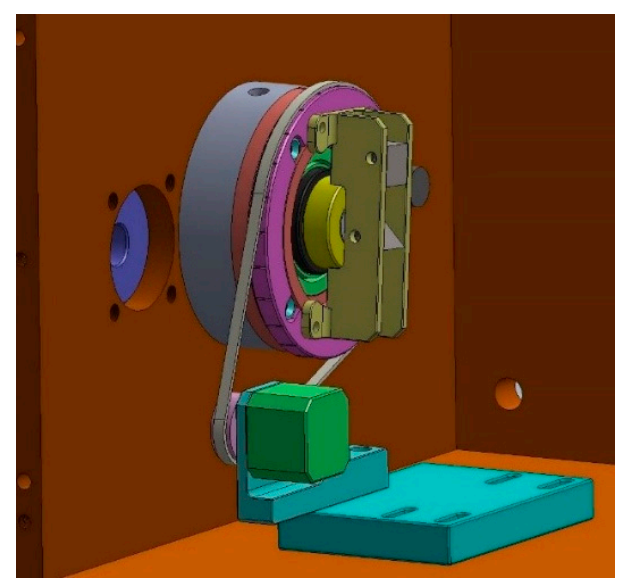

Figure 5. Detailed angled view of seal test bench section of the test rig.

A magnified observation view of the seal-shaft interface is facilitated using a periscope set-up. The stationary housing connects to a mount (purple). A mirror retainer (green) with two strategically angled mirrors fixes on to this mount. A toothed belt (grey) connects the mount and a stepper motor together. The stepper motor is a 2 phase, 4 wire cable, and bipolar motor. It has a step angle of 1.8 degrees and a holding torque of $22 \mathrm{Nm}$. As the stepper motor rotates, the mirror mount will also rotate slowly $360^{\circ}$ providing a magnified view of the seal-shaft interface around the entire circumference.

The shaft speeds selected to replicate the conditions of the helicopter gearbox that the seals will experience in service are presented in Table 3. Rotational speeds of 360 to $6000 \mathrm{rpm}$ on the output shaft replicate various locations of the seal in the gearbox. For example, for a seal located in the input housing, on an $\varnothing 66 \mathrm{~mm}$ shaft, the engine input speed is approximately $6250 \mathrm{rpm}$. This results in a seal surface speed of $21.6 \mathrm{~ms}^{-1}$. However, on the other hand, for a seal located in the output housing, on an $\varnothing 275 \mathrm{~mm}$ shaft, the main rotor speed is approximately $330 \mathrm{rpm}$, resulting in a seal surface speed of $4.8 \mathrm{~ms}^{-1}$. Hence, seal surface speeds between $5-20 \mathrm{~ms}^{-1}$ sufficiently reproduce the conditions of the gearbox. Refer to calculations using Equations (1)-(3) in Table 3. Data for these equations in taken from Table 2.

$$
\begin{gathered}
R P M \text { on output shaft }=R P M \text { on input shaft } \times 3 \\
R P M(n)=f\left(\frac{2}{p}\right) \times 60 \\
R P M \text { on output shaft }=f \times 60 \times 3
\end{gathered}
$$


Table 3. Rotational speeds for testing of frequency, input shaft and output shaft.

\begin{tabular}{ccc}
\hline Frequency $\mathbf{( H z )}$ & Input Shaft $\mathbf{( r p m )}$ & Output Shaft $(\mathbf{r p m})$ \\
\hline 2 & 120 & 360 \\
3 & 180 & 540 \\
5.5 & 330 & 990 \\
7 & 420 & 1260 \\
10 & 600 & 1800 \\
15 & 900 & 2700 \\
20 & 1200 & 3600 \\
25 & 1500 & 4500 \\
30 & 1800 & 5400 \\
33.3 & 1998 & 6000 \\
\hline
\end{tabular}

Following these calculations, the motor operates at frequencies ranging from 2 to $33.3 \mathrm{~Hz}$, producing 120 to $2000 \mathrm{rpm}$ on the input shaft and 360 to $6000 \mathrm{rpm}$ on the output shaft.

A standardized procedure where each seal-sleeve pair operates for a total of $4 \mathrm{~h}$ to ensure uniformity of testing. Each rotational speed in Table 3 above runs for a duration of $20 \mathrm{~min}$, resulting in a total test time of $3 \mathrm{~h}, 20 \mathrm{~min}$. Finally, the test rig continues to run for a further $40 \mathrm{~min}$ at $4500 \mathrm{rpm}$.

Repeat experiments are conducted for the $12 \mathrm{oz}$ seal, where two sets of tests were conducted with all sleeves to confirm reproducibility of results. The Pearson coefficient (r) of each dataset was found using Equation (4). Correlation is 'the degree of association between two random variables $X$ and $Y^{\prime}$. It is expressed by a coefficient that lies between -1 and 1 , known as the Pearson Coefficient, indicating whether there is a positive, negative or no correlation between the data sets. To find the correlation of the results between the repeat experiments, we calculated $\mathrm{r}$ for the speed against temperature for test 1 , and compared it to the $r$ for test 2 . We find the coefficients for the two tests within $1 \%$ of each other, presented in Table 4 below. This provided statistical evidence that the results were reproducible.

$$
r(X, Y)=\frac{\operatorname{cov}(X, Y)}{s_{X} s_{Y}}
$$

where ' $c o v$ ' is the covariance and ' $s_{X}$ ' is the standard deviation.

Table 4. Contact temperatures at the sealing interface for Test $1\left(T_{1}\right)$ and Test $2\left(T_{2}\right)$, reflecting repeat experiments conducted on the $12 \mathrm{oz}$ seal spring against all sleeves. Calculation of Pearson Coefficient ' $r$ ' for statistical validity and reproducibility of experiments.

\begin{tabular}{ccccccccc}
\hline Speed & \multicolumn{2}{c}{ Chrome Oxide } & \multicolumn{2}{c}{ Chrome Plate } & \multicolumn{2}{c}{ Tungsten Carbide } & \multicolumn{2}{c}{ Stainless Steel } \\
\hline rpm & $\mathbf{T}_{\mathbf{1}}$ & $\mathbf{T}_{\mathbf{2}}$ & $\mathbf{T}_{\mathbf{1}}$ & $\mathbf{T}_{\mathbf{2}}$ & $\mathbf{T}_{\mathbf{1}}$ & $\mathbf{T}_{\mathbf{2}}$ & $\mathbf{T}_{\mathbf{1}}$ & $\mathbf{T}_{\mathbf{2}}$ \\
\hline 360 & 297.9 & 295.9 & 298.5 & 298.5 & 298.5 & 300.5 & 301.9 & 300.9 \\
540 & 301.3 & 298.3 & 302.9 & 302.9 & 298.6 & 301.6 & 303.1 & 302.1 \\
990 & 304.1 & 302.1 & 304.8 & 305.8 & 300.2 & 303.2 & 304.2 & 306.2 \\
1260 & 306.2 & 304.2 & 306.9 & 307.9 & 301.5 & 304.5 & 306.1 & 309.1 \\
1800 & 306.3 & 307.3 & 312.0 & 312.0 & 304.0 & 308.0 & 310.7 & 314.7 \\
2700 & 308.3 & 309.3 & 319.4 & 320.4 & 308.9 & 312.9 & 317.4 & 322.4 \\
3600 & 312.8 & 315.8 & 326.7 & 329.7 & 314.7 & 319.7 & 323.4 & 328.4 \\
4500 & 317.1 & 321.1 & 329.5 & 334.5 & 320.9 & 325.9 & 329.5 & 332.5 \\
5400 & 321.4 & 323.4 & 333.5 & 341.5 & 325.4 & 329.4 & 335.0 & 338.0 \\
6000 & 326.3 & 326.3 & 338.6 & 345.6 & 328.6 & 331.6 & 340.9 & 342.9 \\
r & 0.88732 & 0.89276 & 0.89222 & 0.89760 & 0.89763 & 0.89742 & 0.89859 & 0.89480 \\
\hline
\end{tabular}

As seen in Table 4 above, the r-values for all four of the sleeves demonstrate positive correlations with speed. More significantly, a comparison of the correlation values for each sleeve between $T_{1}$ and $T_{2}$ reveals that the measure of association of test 1 and 2 is within 
$1 \%$ of each other. For the $12 \mathrm{oz}$ seal, all graphs in the result section reflect a mean value between the two datasets collected.

\subsubsection{Thermal Imaging Data Collection}

An infrared thermal imaging camera set up in front of the seal test bench enables observation of the test. Figure 6 clearly depicts how the camera is positioned in front of the bench. A two-piece reflective mirror set-up (perpendicular to one another) on a mirror mount connect to a rotating face on the stationary housing as seen in Figure 5. A pulley, made with a toothed belt that mounts on this rotating face and connects to a stepper motor (3:1 transmission ratio), ensures that this mirror mount rotates as the stepper motor operates. These reflective mirrors are at an angle to provide a magnified view of the sealshaft interface, and the rotation of the stepper motor and mirror mount enable that view around the circumference of the seal. This not only provides a clear image of the interface between the seal and shaft, but also ensures investigation of the entire circumference.

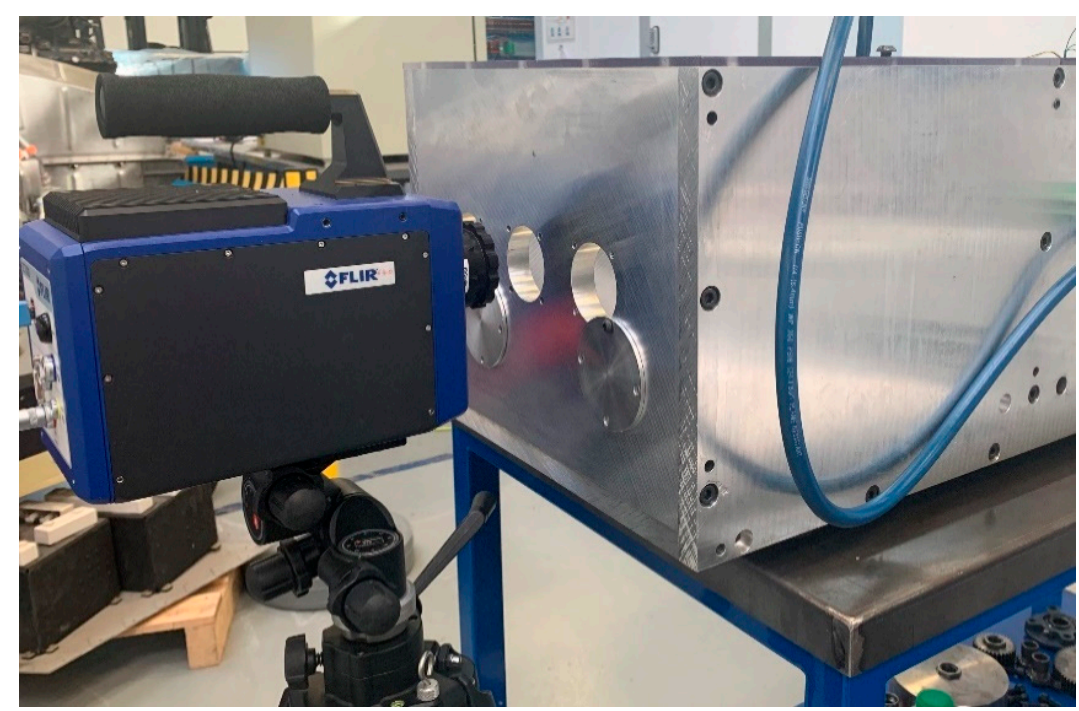

Figure 6. Set up of FLIR thermal imaging camera in front of the seal test bench.

The camera used is an infrared thermal imaging camera, IR FLIR MAX (FLIR SC7000, Wilsonville, OR, USA). This particular series allows capturing accurate temperatures (using FLIR Hypercal $^{\mathrm{TM}}$ ) at high frame rates, while preserving sensitivity as well.

\subsection{Analysis Methods}

\subsubsection{Surface Roughness Measurements}

A ZETA profilometer (Zeta 20, KLA Tencor, Milpitas, CA, USA) is used to take measurements of the surface roughness and obtain 3D imaging of the specimens. This technique uses a broadband and spatially extended light source with an interferometric objective to generate low-coherence interference fringes as the instrument scans along the optical axis of the system. The surface topography of a sample is derived from these interference fringes. Mountains Map software (version: 8.2.9468) post-processes the raw data collected.

\subsubsection{Thermal Imaging Measurements}

Research IR thermal analysis software enables post-test data processing. This software is a measurement, recording and analysis software that comes with the FLIR camera. As mentioned in its description, "ResearchIR performs real-time image analysis, with an extensive set of measurement tools including spots, lines, and areas. Export image and plot data graphically as a Bitmap or CSV file for reporting and analysis in other software programs" [26]. This enables data analysis of the thermal imagery. 


\subsection{Control Methods}

A control test to account for the emissivity of the various components ensures that this does not affect the final contact temperatures observed at the interface. The thermal imaging camera is an infrared camera that measures the thermal radiation from each surface. Varying surfaces emit thermal radiation with differing effectiveness and emissivity refers to the effectiveness of a surface in emitting energy as thermal radiation. This control measure includes finding the emissivity of the components and ensures calibration of the camera to account for this when collecting data.

An insulating glass sheet covers the entire rig, allowing it to 'thermally soak' for some given time period. This ensures that all the components within the insulated rig are the same temperature after some amount of time i.e., the ambient temperature of the room.

The thermal imaging camera captures the radiant emittance, $j^{*}$ from each body and uses the inbuilt algorithm to calculate the temperature. For this control experiment, the camera object parameters are set to default with an emissivity of 1 . The radiant emittance, $j^{*}$ is defined in Equation (5).

$$
j^{*}=\varepsilon \sigma \mathrm{T}^{4}
$$

$j^{*}=$ Radiant emittance $\mathrm{Jm}^{-2} \mathrm{~S}^{-1}$

$\varepsilon=$ Emissivity

$\sigma=$ Stefan Boltzman constant $\mathrm{Wm}^{-2} \mathrm{~K}^{-4}$

$T=$ Temperature $K$

Thermal images of the rig taken once the 'thermal soaking' is complete display that the temperature of all the components vary by $\pm 1{ }^{\circ} \mathrm{C}$. Ideally, all components will have a homogenous temperature due to the thermal soaking described above. However, the variance in temperature for each component within a range of $\pm 1{ }^{\circ} \mathrm{C}$ reveal that calibration of the camera is necessary.

The emissivity correction is a control measure that ensures temperature data taken is reliable and not skewed due to emissivity of the components.

\section{Results}

\subsection{Seal Spring Applied Load}

The garter spring provides and maintains radial force of the lip on the sleeve surface over the life of the seal. The load of the spring $(P)$ is the initial tension $\left(P_{1}\right)$ plus the load due to spring rate (kf) (Equation (6)). The total load of this 12 ounce-force seal is $20.9 \mathrm{~N}$. Calculation of the radial load of the seal $\left(P_{\mathrm{r}}\right)$ includes using the circumferential load $(\mathrm{Pc})$ (Equation (7)). $\mathrm{D}_{2}$ is the maximum extended inside diameter of the seal. The circumferential load, Pc, of this seal is $0.1336 \mathrm{~N} / \mathrm{mm}$. The final radial force of the seal is calculated using Equation (8), and is $20.9 \mathrm{~N}$ [27]. The selection of the seal spring loads is in line with the standard sealing practices for this particular application, helicopter gearboxes. The seals are placed in the input and output locations of an intermediate helicopter gearbox.

$$
\begin{gathered}
P=P_{1}+k f \\
P_{c}=\frac{2 P}{D_{2}} \\
P_{\mathrm{r}}=P_{\mathrm{c}} \times \pi \times 2 r
\end{gathered}
$$

Table 5 below displays the circumferential and radial load for each of the three seals included in this test. 
Table 5. Radial and Circumferential seal loads for varying seal spring.

\begin{tabular}{ccc}
\hline Seal Spring & $\begin{array}{c}\text { Circumferential Load } \\
\text { (N/mm) }\end{array}$ & Radial Load (N) \\
\hline 8.5 oz spring & 0.0923 & 14.5 \\
12 oz spring & 0.1336 & 20.9 \\
14 oz spring & 0.1521 & 23.9 \\
\hline
\end{tabular}

At rotational speeds of $6000 \mathrm{rpm}$, an excess temperature rise of $40 \mathrm{~K}$ is expected. Since $6000 \mathrm{rpm}$ is the maximum rotational speed in this experiment, it is the maximum acceptable value for excess temperature at the interface.

Figure 7 below displays four plots and each plot demonstrates the maximum contact temperature at the sealing interface as a function of shaft rotational speed for four sleeves.

(a)

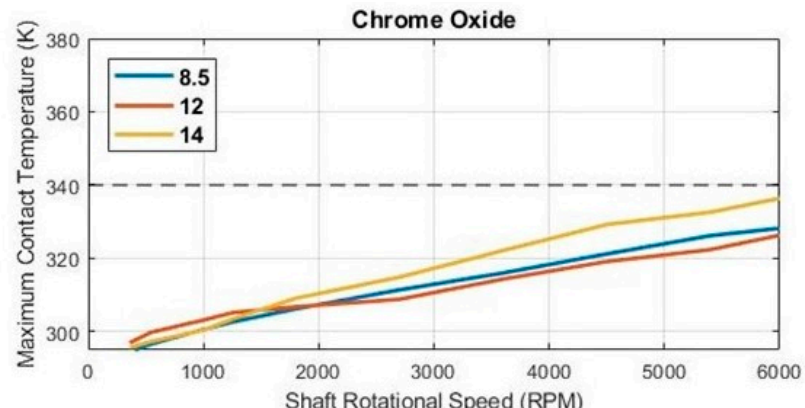

(c)

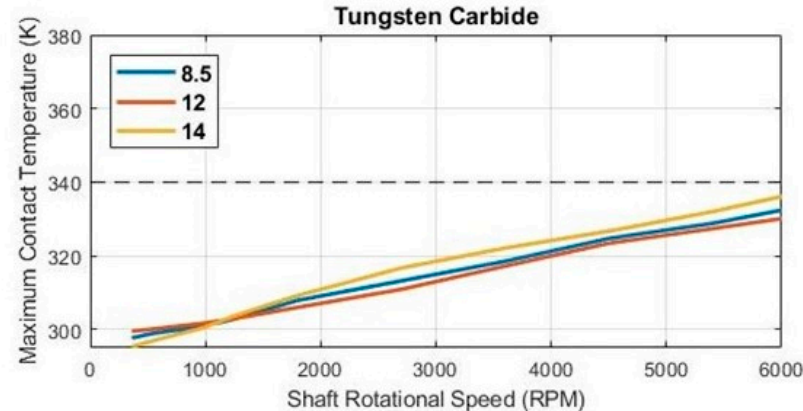

(b)

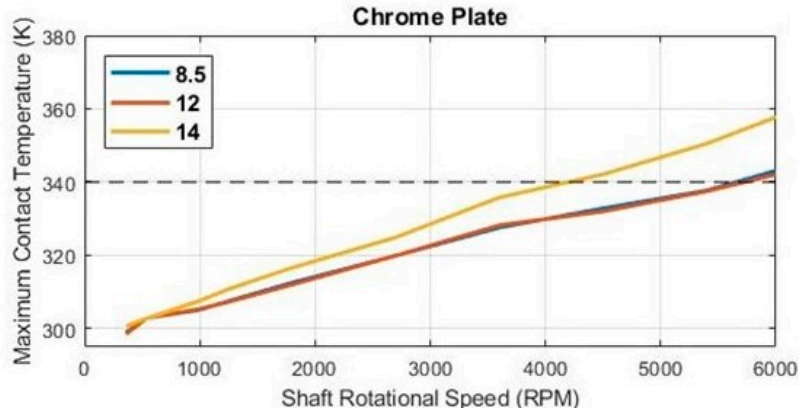

(d)

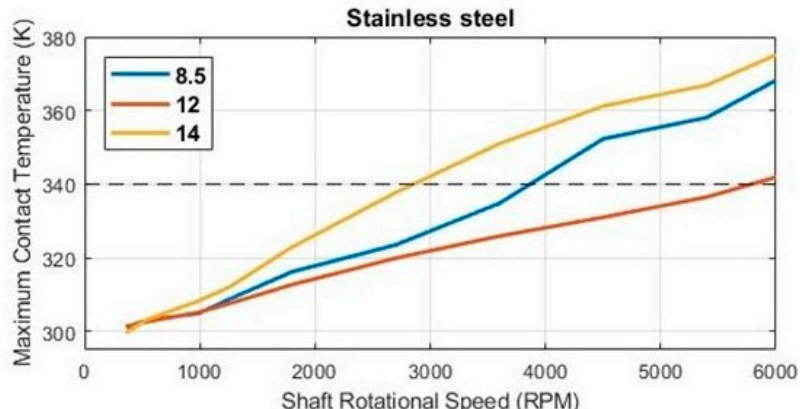

Figure 7. Maximum contact temperature at the sealing interface as a function of shaft speed for (a) Chrome Oxide (b) Chrome Plate ( 8.5 and $12 \mathrm{oz}$ results overlap with one another and display almost identical trends, making the $8.5 \mathrm{oz}$ line difficult to spot) (c) Tungsten Carbide and (d) Stainless Steel.

Qualitatively, Figure 7 reveals that the $14 \mathrm{oz}$ spring exhibits the highest increase in temperature for all the sleeves. Given that all the sleeves are initially at a temperature of 300 $\mathrm{K}$, a recorded temperature of more than $340 \mathrm{~K}$ is undesirable according to what we expect. At a closer look, the maximum excess temperature for $\mathrm{CO}$ and TC does not exceed $340 \mathrm{~K}$. However, for the CP and SS sleeves, the final temperature at $6000 \mathrm{rpm}$ is $360 \mathrm{~K}$ and $375 \mathrm{~K}$. This is higher than the expected temperature rise by a factor of 1.5 and 1.9 respectively. From the three springs, this provides the highest radial load and is consequently the case that exhibits highest excess temperatures for all four sleeves.

For the $8.5 \mathrm{oz}$ spring, the SS sleeve alone records excessively higher temperatures. For the $\mathrm{CP}, \mathrm{CO}$ and TC sleeves, the 8.5 and $12 \mathrm{oz}$ springs reach roughly the same temperatures. For the SS sleeve, the $8.5 \mathrm{oz}$ spring reaches approximately $368 \mathrm{~K}$, which is not far behind the $14 \mathrm{oz}$ seal for this case. Although it did not reach undesirable temperatures in all of the tests, the $8.5 \mathrm{oz}$ seal is not optimal. While the spring load is considerably lower in this case, results demonstrate that they still may reach higher temperatures. However, while the observed higher temperatures in this test case is partly due to the SS sleeve, the $12 \mathrm{oz}$ 
spring in contrast did not reach these temperatures. This indicates that the load provided by the $8.5 \mathrm{oz}$ spring is partly responsible for this increase in temperature.

In contrast to the previous two springs, the 12 oz spring exhibited consistent temperatures within the desired range for all test cases as demonstrated in Figure 7 below. It is the optimum spring load, evidenced by the results that it did not exceed the expected $40 \mathrm{~K}$ temperature rise, even for the SS sleeve that is poor performing as will be noted in further sections.

\subsection{Surface Coatings}

To analyse the performance of each surface coating and draw a comparison between them, Figures 8-10 depict the maximum contact temperature as a function of shaft speed for each seal spring. This enables a comparison between the four sleeves for each seal spring load. The initial temperature at the contact interface lies between 295 and $300 \mathrm{~K}$.

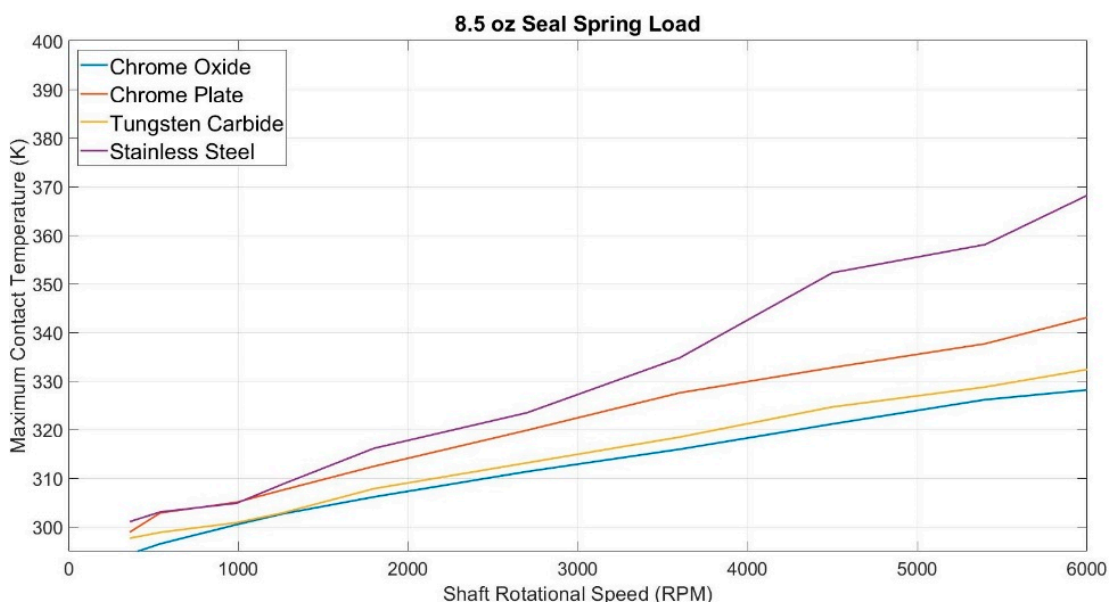

Figure 8. Maximum contact temperature at sealing interface for all $8.5 \mathrm{oz}$ spring loads, comparing temperatures reached for $\mathrm{CO}, \mathrm{CP}, \mathrm{TC}$ and SS sleeves.

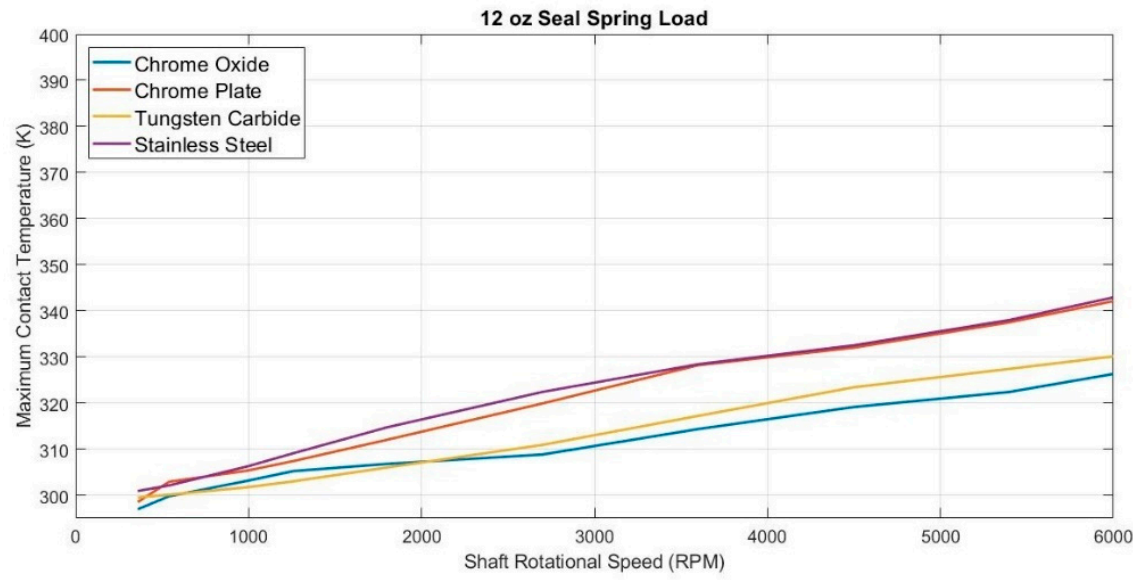

Figure 9. Maximum contact temperature at sealing interface for all $12 \mathrm{oz}$ spring loads, comparing temperatures reached for $\mathrm{CO}, \mathrm{CP}, \mathrm{TC}$ and SS sleeves, reflecting mean values of two datasets taken for repeat experiments. 


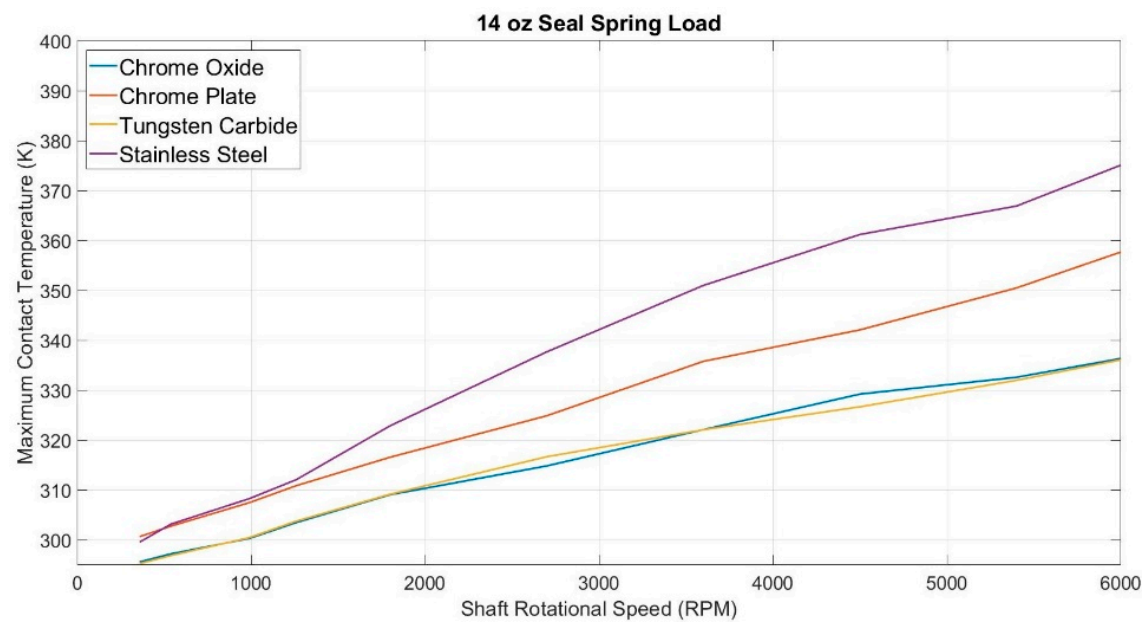

Figure 10. Maximum contact temperature at sealing interface for all $14 \mathrm{oz}$ spring loads, comparing temperatures reached for $\mathrm{CO}, \mathrm{CP}, \mathrm{TC}$ and SS sleeves.

Figure 8 below displays the temperatures at the sealing interface for the $8.5 \mathrm{oz}$ spring. From this plot, it is quantitatively apparent that the SS shaft experiences noticeably higher temperatures than expected, reaching almost $370 \mathrm{~K}$. This is an approximate increase of $70 \mathrm{~K}$ from the initial temperature, higher than the expected temperature rise by a factor of 1.75 . The temperature increase noted in the $\mathrm{CP}$ sleeve comes in next, reaching a temperature of just above $340 \mathrm{~K}$. This is a temperature rise of approximately $40 \mathrm{~K}$, within the expected range of temperature increase. The TC and CO sleeves remain at temperature rises well below the expected amount at near $330 \mathrm{~K}$.

Figure 9 below displays temperatures at the sealing interface for the $12 \mathrm{oz}$ spring. It is worth nothing that there are no exceptionally high temperatures observed with any sleeves here. Quantitatively, the CP and SS sleeves reach higher temperatures than the TC and the $\mathrm{CO}$ by $10-15 \mathrm{~K}$. While the final temperatures for these two sleeves at the interface are not that much higher than the expected range of values, the results are consistent with Figure 8, where the CP and SS sleeves result in higher temperatures than TC and CO.

Figure 10 below displays the displays temperatures at the sealing interface for the $14 \mathrm{oz}$ spring. In this case, it is qualitatively evident that the SS and CP sleeves reach relatively higher temperatures in contrast to the TC and the CO sleeves. Quantitatively, the SS sleeve has a temperature rise of $75 \mathrm{~K}$ and the $\mathrm{CP}$ sleeve has a temperature increase of $60 \mathrm{~K}$. The remaining two sleeves both continue to remain within the expected range of temperature increase, not exceeding an increase of greater than $40 \mathrm{~K}$. These results are also consistent with Figures 8 and 9 of SS and CP sleeves demonstrating higher temperature increase at the sealing interface.

Consistent results confirm the use of SS and CP sleeves as seal-mating sleeve surfaces have exceptionally higher temperature increase at the sealing interface in contrast to other coatings, i.e., TC and CO. This is the case for all seal springs at all rotational speeds.

These findings emphasize on the significance of surface coatings for the seal counter surfaces to control temperatures at the contact interface of the sealing system. It builds upon already established literature and guidelines that explain how the hardness and other properties of the surface coated sleeve enable a successful seal [5,6]. Additionally, guidelines [28] specify that chrome plating is a technique that is undesirable for a few reasons, most notably their interaction with the seal over time. They state that the chromeplated sleeve will 'polish' overtime and become smoother. Evidenced from the higher temperatures at the contact interface in the case of $\mathrm{CP}$ sleeves, this may be a reason that contributes to wear and polish at the interface. Thus, increased temperatures may be causing or aggravating wear in these cases. 


\subsection{Surface Roughness}

Different standards for radial oil seals specify that the running surface for oil seals should meet the following requirements outlined in Table 6 below. The surface roughness of the sleeve must range between Ra $0.2 \mu \mathrm{m}$ to $0.8 \mu \mathrm{m}$ according to DIN 3760/61 [4,10], while ISO 6194 and RMA OS-1-1 [3,29] provide a smaller range of Ra $0.2 \mu \mathrm{m}$ to $0.5 / 0.43 \mu \mathrm{m}$. The performance of a seal is heavily reliant on the mating surface topography, including the surface roughness and texture. Plunge grinding is the preferred method of surface finish as other methods result in higher friction, and as a result, higher temperatures [5].

Table 6. Specifications for Radial Lip Seals Mating Surfaces (Sleeve) according to ISO, DIN \& RMA Standards.

\begin{tabular}{cccc}
\hline Title & DIN $3760 *$ & ISO 6194-1 $* *$ & RMA OS-1-1 *** \\
\hline $\begin{array}{c}\text { Shaft surface } \\
\text { roughness }\end{array}$ & Ra 0.2 to $0.8 \mu \mathrm{m}$ & Ra 0.2 to $0.5 \mu \mathrm{m}$ & Ra 0.2 to $0.43 \mu \mathrm{m}$ \\
\hline
\end{tabular}

${ }^{*}$ DIN $=$ Deutsches Institut für Normung. ${ }^{* *}$ ISO = International Organization for Standardization. ${ }^{* * *}$ RMA $=$ Rubber Manufacturers Association.

Table 7 below summarizes the roughness parameters of the four sleeves. The Ra value refers to the arithmetic average height of the surface roughness profile. Alternatively, it is known as the centerline average and is the most basic measure of the surface roughness of any specimen. $\mathrm{Rp}$ and $\mathrm{Rv}$ values refer to the roughness peaks and roughness valleys. Rp is defined as the maximum height of the peak above the mean line, and $\mathrm{Rv}$ is defined as the maximum depth of the valley below the mean line [30].

Table 7. Sleeve Surface Roughness (units: $\mu \mathrm{m}$ ).

\begin{tabular}{cccc}
\hline Sleeve Coatings & Ra & Rp & Rv \\
\hline Chrome Plate & 0.174 & 1.115 & 0.585 \\
Chrome Oxide & 0.135 & 1.699 & 1.115 \\
Tungsten Carbide & 0.187 & 0.471 & 0.689 \\
Stainless Steel & 3.143 & 4.145 & 2.178 \\
\hline
\end{tabular}

Sections 4.1 and 4.2 demonstrate clearly that the SS and CP sleeves exhibit higher temperatures at the sealing interface over the others. The surface of SS sleeve is microscopically far rougher than the other three sleeves. Evidenced by the fact that it consistently has higher contact temperatures in all of its test cases, the microscopically rough surface is a contributing factor for this. Additionally, the SS is not surface coated or finished to any specifications, another significant reason for the overall higher contact temperatures observed in this specimen.

\section{Discussion}

This study considers three important parameters to investigate their effect on the contact temperatures at the sealing interface: seal spring loads, surface coatings and surface roughness.

The total load of the sealing system is a combination of the load provided by the elastomer and the garter spring. The garter spring is designed to maintain a constant radial force on the seal lip, even as the elastomer ages and the load decreases. An increasing radial load results in frictional forces to increase at the interface [31], which would cause temperatures to rise. However, it has been shown that increasing temperatures at the interface causes contact forces to subsequently decrease [32], which would likely result in a decrease in the rate of change of temperature rise. Thus, it is not as straight forward as higher radial load will result in higher temperatures and vice versa. In this study, an optimum seal of $12 \mathrm{oz}$ exhibits controlled temperatures at the contact interface. A lower seal spring of $8 \mathrm{oz}$ results in slightly higher temperatures, as does a $14 \mathrm{oz}$ seal spring. This 
is unexpected as a lower radial load would decrease friction at the interface and thus, presumably cause temperatures to decrease. However, for this application, findings show that a lower seal spring of $8 \mathrm{oz}$ does not cause a reduction in contact temperatures. This may be due to an improper formation of the dynamic seal gap with this applied force, resulting in increased friction at the interface. It is difficult to predict with certainty why a $12 \mathrm{oz}$ seal spring exhibited optimum performance. However, it can be concluded that for such applications, a $12 \mathrm{oz}$ seal spring reaches optimum temperatures at the contact interface-higher and lower values result in increase of temperature.

The application of thin and hard coatings to metals with lower wear resistance is a practice that has improved the tribological interaction of contacting bodies and surfaces. Components operating in high temperature environments like gas turbine engines would experience premature wear, damage and failure without protective hard coatings [33].

The CP sleeve experienced the highest contact temperatures from the three coated sleeves, albeit not as high as the uncoated SS sleeve. The SS sleeve, in contrast, experienced the highest contact temperatures from all the four sleeves tested. The SS sleeve was uncoated and its surface roughness was not within the desired ranges as required by the ISO, and DIN standards. The CP sleeve fulfilled the surface roughness requirements, so its failure in terms of contact temperature falls on the nature of the coating. The $\mathrm{CP}$ coating is one that has become seldom used in the aerospace industry and due to the implementations of EU directives such as 1999/13/EC (VOC), 2011/65/EU (RoHS), and 2012/19/EU (WEEE) [20,34-36], alternatives to such a coating is encouraged. Additionally, it has a nature of polishing in easily overtime [28]. This polishing in effect will result in a smoother surface than it initially was as the roughness peaks are removed by this phenomenon. This can eventually also result in wear of the sleeve surface. Smooth surfaces are considered undesirable for seal counter surfaces as they will result in more friction at the interface, and as a result, higher contact temperatures.

This is why this CP sleeve experienced higher contact temperatures than TC and CO. However, the SS sleeve has a higher roughness and is uncoated, both of which contribute to the higher friction, resulting in excessively higher temperatures at the interface in all test cases.

Micro roughness, groove textures and other laser-textured surfaces are known to reduce the friction at contacting interfaces [37]. Table 5 presents the surface roughness range for sleeves as recommended by the standards. These standards also specify that a plunge ground surface finish is recommended, as the micro roughness patterns on the surface are a critical aspect of achieving an effective sealing system. Lead on the sleeve surface is also undesirable and ISO 6194 and DIN $3761[3,4,10]$ recommend zero lead on the sleeve surface. Any lead, coupled with the direction of shaft rotation may result in pumping of oil toward either side [38] which can starve the interface of lubricant. Thus, the surface roughness is critical in controlling friction and temperatures at the sealing interface.

An uncoated SS shaft or sleeve is not finished to the desired specifications, and as we observe in this study, does not perform up to the required standards in terms of contact temperatures at the sealing interface. In this study, the three coated sleeves (TC, CO, CP) are surface finished to the desired standard, while the SS sleeve is generically manufactured without any surface finishing process. While this results in a flawed comparison from one aspect, the test is designed this way to draw a comparison between sleeves that are coated and surface finished as opposed to using a plain SS sleeve/shaft that has not undergone any surface treatment.

The first finding is that a microscopically rougher shaft will result in increased temperatures at the sealing interface. The flaw in the study is that it is difficult to pinpoint whether the temperature rise is attributed to the sleeve being rougher or because it is uncoated, as an uncoated SS sleeve with the correct roughness has not been studied here. However, previous studies have established that a surface that is 'too rough' is undesirable, just as a perfectly smooth (super-finished) surface is. A shaft surface 'rougher' than required can result in excessive and undesirable wear, thus decreasing seal life. Consequently, a shaft 
surface 'too smooth' can also be detrimental as the seal will not wear in as required, potentially resulting in high leakage levels. Horve concluded that this phenomenon is a critical aspect necessary to achieve reliable seal performance [39]. Thus, it is not presumptuous to conclude that the microscopically rougher surface of the SS sleeve contributes to higher temperatures at the sealing interface.

\section{Conclusions}

This experimental study reveals the maximum temperatures at the sealing interface for a number of seal-sleeve combinations at sliding velocities of $5-25 \mathrm{~ms}^{-1}$. The results demonstrate that a $12 \mathrm{oz}$ spring load is an optimum load, as higher spring loads of $14 \mathrm{oz}$ result in undesirable and higher temperatures at the sealing interface. Consequently, a lower spring load of $8.5 \mathrm{oz}$ does not result in lower temperatures than observed in the $12 \mathrm{oz}$ spring as one might expect. Depending on the requirement of the application, a $14 \mathrm{oz}$ spring may be optimal if controlled leakage is more important than controlled contact temperature. In contrast, an $8.5 \mathrm{oz}$ spring may be optimal if wear is a more poignant concern for that application. However, for applications where excess temperature at the sealing interface is a high priority concern, $12 \mathrm{oz}$ seal spring provides an optimal sealing environment for controlled temperature increase.

The seal-running surface, the sleeve, is of great importance in achieving a successful sealing environment. The presence of state-of-the-art seal specification standards (described in 4.3 depict the importance of the surface roughness of the sleeve. The microscopic roughness of the SS is higher than the other three sleeves, mainly because it has not been finished to a desired standard. The results of this sleeve reveal higher contact temperatures with all seal springs, which is due to this microscopically rough surface. It will result in higher friction at the interface, resulting in higher temperatures at the sealing interface. Additionally, the SS does not have a surface coating. Evidenced by the disparity of temperature increase for this sleeve in particular in contrast to others, the significance of an appropriate surface coating on the sleeve is re-enforced.

The results from the SS clearly demonstrate the need for surface coating and its role in contact temperature at the sealing interface. The CP sleeve also exhibits higher contact temperatures over the TC and CO sleeve, albeit lower contact temperatures than the SS sleeve. CP sleeves are not as highly recommended as seal-mating surfaces anymore as they have been in the past. They are undesirable as they polish in over time; resulting in 'smoother' surfaces (smoother than the recommended roughness guidelines) and cause wear in the system. This study concludes that another reason for its poor performance is the tendency to have higher contact temperatures at the sealing interface, which will only aggravate wear of the seal lip through elastomer aging and other mechanisms.

Results from the TC and CO sleeves consistently exhibit excess temperature of $40 \mathrm{~K}$ or less at the sealing interface, indicating that they are ideal sleeve surface coatings in terms of temperature control. However, other factors that may contribute to the increase of contact temperatures include long-term wear, vibration in the system and shaft eccentricity. Evaluation of these factors was outside the scope of this work.

Future work can benefit from a deeper insight into the surface micro roughness of the sleeves, including the texture and lead. This may provide more insight into specific micro patterns, grooves or textures that are causing contact temperatures to increase and thus, detrimental to the overall success of the sealing system.

Author Contributions: Conceptualization, S.S., S.D.G., S.M.D., and B.C.R.; methodology, S.S.; software, S.S.; validation, S.S.; data curation, S.S.; formal analysis; S.S., investigation, S.S.; writingoriginal draft, S.S., writing-review \& editing, S.S., S.D.G., S.M.D., and B.C.R.; supervision, S.D.G., S.M.D., and B.C.R.; resources, S.D.G., S.M.D., and B.C.R.; project administration, S.D.G., S.M.D., and B.C.R. All authors have read and agreed to the published version of the manuscript.

Funding: This work was supported the INNOVATIVE doctoral programme [project NO. 665468]. The INNOVATIVE programme is partially funded by the Marie Curie Initial Training Networks (ITN) action; and partially by the Institute for Aerospace Technology (IAT) at the University of Nottingham. 
Data Availability Statement: Data available in a publicly accessible repository. The data presented in this study are openly available in [Mendeley Data] at [doi 10.17632/htkd85nsk4.1].

Acknowledgments: Authors would like to thank Leonardo MW Ltd. for supporting this work through a joint collaboration with University of Nottingham. The authors acknowledge that parts of this work were inspired by project PROTEUSS which has received funding from the Clean Sky 2 Joint Undertaking under the European Union's Horizon 2020 research and innovation program (grant agreement number 738176).

Conflicts of Interest: The authors declare no conflict of interest. The funders had no role in the design of the study; in the collection, analyses, or interpretation of data; in the writing of the manuscript, or in the decision to publish the results.

\section{References}

1. Yildiz, M. Modeling and Simulation of Oil Leakage in Radial Lip Seals. Master's Thesis, Middle East Technical University, Ankara, Turcia, 2010.

2. $\quad$ Roche, B.P. Alternatives in Gearbox Seals for Main Drive Gearboxes; Technical University of Lodz: Lodz, Poland, 2006; pp. 1-8.

3. ISO 6194-1:2007, Rotary shaft lip-type seals incorporating elastomeric sealing elements—Part 1: Nominal dimensions and tolerances. Geneva, Switzerland, 2007. Available online: https://www.iso.org/obp/ui/\#iso:std:iso:6194:-1:ed-2:v1:en:sec:6.1 (accessed on 29 January 2021).

4. DIN 3760 1996-09; Radial shaft sealing rings. Germany, 1996. Available online: https://www.beuth.de/en/standard/din-3760/2 815256 (accessed on 29 January 2021).

5. Trelleborg Sealing Solutions. Radial Oil Seal; Trelleborg Sealing Solutions: Schaumburg, IL, USA, 2009.

6. Dichta. Rotary Shaft Seals; Dichta SA: Balerna, Switzerland. Available online: http://www.dichta.com/products/Rotary-ShaftSeals.html (accessed on 29 January 2021).

7. Ding, L.; Axinte, D.; Butler-Smith, P.; Hassan, A.A. Study on the characterisation of the PTFE transfer film and the dimensional designing of surface texturing in a dry-lubricated bearing system. Wear 2020, 448-449, 203-238. [CrossRef]

8. Rinnbauer, M. Technical Elastomers; Freudenberg Sealing Technologies: Baden-Württemberg, Germany, 1999 ; Volume 89.

9. Baart, P. Grease lubrication in radial lip seals. Eng. Tribol. 2009, 223, 347-358.

10. DIN 3761-1_1984-01, Radial shaft seals for motor vehicles. Germany, 1984. Available online: https://www.beuth.de/de/norm/ din-3761-1/1087633 (accessed on 29 January 2021).

11. Bhushan, B.; Gupta, B.K. Handbook of Tribology: Materials, Coatings, and Surface Treatments; Krieger Publishing Company: Malabar, FL, USA, 1997.

12. Fotovvati, B.; Namdari, N.; Dehghanghadikolaei, A. On coating techniques for surface protection: A review. J. Manuf. Mater. Process. 2019, 3, 28. [CrossRef]

13. Zhuk, Y. Nanostructured CVD tungsten carbide coating on aircraft actuators and gearbox shafts reduces oil leakage and improves durability. J. Mater. Eng. Perform. 2019, 28, 1914-1923. [CrossRef]

14. Stakenborg, M.J.L. On the sealing mechanism of radial lip seals. Tribol. Int. 1988, 21, 335-340. [CrossRef]

15. Salant, R.F.; Wang, L.; Wang, Y.; Guo, F.; Lv, M.; Jia, X. The effect of aging in oil on the performance of a radial lip seal. Tribol. Int. 2014, 78, 187-194.

16. Tzanakis, I.; Conte, M.; Hadfield, M.; Stolarski, T.A. Experimental and analytical thermal study of PTFE composite sliding against high carbon steel as a function of the surface roughness, sliding velocity and applied load. Wear 2013, 303, 154-168. [CrossRef]

17. Horve, L. The Effect of Operating Parameters Upon Radial Lip Seal Performance; SAE International: Warrendale, PA, USA, 2018.

18. Odhiambo, J.G.; Li, W.; Zhao, Y.; Li, C. Porosity and its significance in plasma-sprayed coatings. Coatings 2019, 9, 460. [CrossRef]

19. Sartwell, B.D.; Legg, K.; Catalyst, R.; Bodger, B. HVOF Thermal Spray Coatings as an Alternative to Hard Chrome Plating on Military and Commercial Aircraft. In Proceedings of the AESF/EPA Conference for Environmental Excellence, Orlando, FL, USA, 28-30 January 1999.

20. Schopphoven, T.; Gasser, A.; Wissenbach, K.; Poprawe, R. Investigations on ultra-high-speed laser material deposition as alternative for hard chrome plating and thermal spraying. J. Laser Appl. 2016, 28, 022501.

21. Picas, J.A.; Forn, A.; Matthäus, G. HVOF coatings as an alternative to hard chrome for pistons and valves. Wear 2006, $261,477-484$. [CrossRef]

22. Hardide- $A$; Hardide Coatings Limited: Bicester, UK, 1869; Volume 44, pp. 1-2.

23. Legg, K.; Sartwell, B.; Rowan Technology Group; Naval Research Laboratory. Hard Chromium Alternatives Team Update-Improving Performance While Reducing Cost the Hard Chrome Alternatives Team (HCAT) is a Joint Effort by the Defense Performance and Acceptable Cost, it Has Been Found that Performance Is usually for more Informa; Rowan Technology Group: Libertville, IL, USA; Naval Research Laboratory: Washington, DC, USA, 2000.

24. Department of Defense, Performance Specification DOD-PRF-85734A, US government, 2004. Available online: http:/ / everyspec com/DoD/DoD-PRF-SPECS / download.php?spec=DOD-PRF-85734A.009395.PDF (accessed on 29 January 2021).

25. Shell Aeroshell 555; Material Safety Data Sheet; OSHA: Washington, DC, USA, 2008; pp. 1-5.

26. FLIR. FLIR Camera-ResearchIR Description; FLIR: Willsonville, OR, USA, 2020. 
27. Associated Spring. Engineering Guide to Spring Design; Associated Spring: Bristol, CT, USA, 2005.

28. Greene Tweed and Co. Surface Finish Guidelines Datasheet; Greene Tweed: Charlotte, NC, USA, 2007.

29. Rubber Manufacturers Association, RMA OS-1-1, Oil Seal Technical Bulletin-Shaft Finish Requirements for Rotary Lip Seals. Washington, DC, USA. Available online: https://standards.globalspec.com/std/1196809/OS-1-1 (accessed on 29 January 2021).

30. Gadelmawla, E.S.; Koura, M.M.; Maksoud, T.M.A.; Elewa, I.M.; Soliman, H.H. Roughness parameters. J. Mater. Process. Technol. 2002, 123, 133-145. [CrossRef]

31. Girişta, V.; Kaya, I.; Parlar, Z. The effect of interference on the leakage performance of rotary lip seals. Int. J. Environ. Sci. Technol. 2019, 16, 5275-5280. [CrossRef]

32. Tasora, A.; Prati, E.; Marin, T. A method for the characterization of static elastomeric lip seal deformation. Tribol. Int. 2013, 60, 119-126. [CrossRef]

33. Gheisari, R.; Polycarpou, A.A. Tribology of selected hard coatings for oil and gas applications up to $450{ }^{\circ} \mathrm{C}$. Tribol. Lett. 2019, 67 , 1-16. [CrossRef]

34. European Union, Council Directive 1999/13/EC of 11 March 1999 on the limitation of emissions of volatile organic compounds due to the use of organic solvents in certain activities and installations, European union, 1999. Available online: https://eur-lex. europa.eu/LexUriServ / LexUriServ.do?uri=CELEX:31999L0013:en:HTML (accessed on 29 January 2021).

35. European Union, Directive 2011/65/EU of the European Parliament and of the Council of 8 June 2011 on the restriction of the use of certain hazardous substances in electrical and electronic equipment Text with EEA relevance, European union, 2011. Available online: https: / / eur-lex.europa.eu/legal-content/EN/TXT/?uri=CELEX\%3A32011L0065 (accessed on 29 January 2021).

36. European Union, Directive 2012/19/EU of the European Parliament and of the Council of 4 July 2012 on waste electrical and electronic equipment (WEEE) Text with EEA relevance, European union, 2012. Available online: https:/ / eur-lex.europa.eu/ LexUriServ/LexUriServ.do?uri=OJ:L:2012:197:0038:0071:en:PDF (accessed on 29 January 2021).

37. Yu, X.Q.; He, S.; Cai, R.L. Frictional characteristics of mechanical seals with a laser-textured seal face. J. Mater. Process. Technol. 2002, 129, 463-466. [CrossRef]

38. Cohen, D.K.; Smith, S.; Novak, E.L.; Masters, A.T. Measuring surface texture and shaft lead angle of dynamic sealing systems. Quality Digest, 2011. Available online: https:/ / www.qualitydigest.com/inside/metrology-news/measuring-surface-textureand-shaft-lead-angle-dynamic-sealing-systems-030811 (accessed on 19 September 2019).

39. Horve, L. The Correlation of Rotary Shaft Radial Lip Seal Service Reliability and Pumping Ability to Wear Track Roughness and Microasperity Formation; SAE Technical Paper Series; SAE International: Warrendale, PA, USA, 1991. 